Article

\title{
Power Controllable LED System with Increased Energy Efficiency Using Multi-Sensors for Plant Cultivation
}

\author{
Yong Deok Ahn ${ }^{1}$, Sungwoo Bae ${ }^{2}$ and Suk-Ju Kang ${ }^{1, *}$ \\ 1 Department of Electronic Engineering, Sogang University, Seoul 04107, Korea; ahnyd09@gmail.com \\ 2 Department of Electrical Engineering, Hanyang University, Seoul 04763, Korea; swbae@hanyang.ac.kr \\ * Correspondence: sjkang@sogang.ac.kr; Tel.: +82-2-705-8466
}

Academic Editor: Jianlin Li

Received: 11 September 2017; Accepted: 9 October 2017; Published: 14 October 2017

\begin{abstract}
In this paper, a power-controllable light emitting diode (LED) control system is proposed for plant cultivation. The proposed LED system measures environmental data, such as the distance between the plant and LED system using an infrared sensor and the ambient illuminance based on an illuminance sensor. Then, it converts the illuminance to the photosynthetic photon flux density (PPFD) for plant cultivation. It analyzes the relationship between the data and LED PPFD, and generates an optimal pulse width modulation (PWM) signal. Therefore, it controls the LED PPFD dynamically. The proposed LED system is also implemented in hardware, which consists of red and blue LED arrays with suitable wavelengths and a micro-controller. In the experimental results, the proposed LED system preserved the target PPFD regardless of the change of the distance and ambient PPFD. Additionally, the proposed LED system maximally reduced the power consumption of a conventional system by up to $68 \%$.
\end{abstract}

Keywords: light emitting diode (LED); power control; lighting control

\section{Introduction}

These days, food shortages have become a significant concern because of the volatility of outdoor plant production caused by unusual weather [1]. In this case, artificial light for plant cultivation is needed, and a technique to reduce its energy and enhance its efficiency is also required [2]. It is also used in conjunction with renewable energy systems, such as offshore wind power generators incorporating plant cultivation systems [3]. In this case, it is important to maximize the energy efficiency by reducing the power consumption in plant cultivation. The light emitting diode (LED) is one of the most popular lighting devices because they have high efficiency, a long lifetime, and high controllability [4] compared to conventional lighting devices, such as cold cathode fluorescent lamps (CCFLs). Currently, LEDs with various wavelengths have been developed, and plant cultivation techniques based on these LED devices have been studied [5]. In this case, a light control system for LED devices is the most important component because it significantly affects the productivity and quality of the plants [6]. Therefore, it is very important to have a system that can control the optimum brightness depending on the plant. Especially, it is very important to control the brightness by considering the environmental factors because it affects the plants by combining the brightness of the LED and the ambient light.

In this paper, a power-controllable LED control system that can consider environmental factors is proposed for plant cultivation. The proposed LED system measures the ambient illuminance using an illuminance sensor for calculating the photosynthetic photon flux density (PPFD) and measures the plant-LED distance using an infrared sensor. Then, the ambient illuminance is converted into the 
PPFD for plant cultivation, and it calculates the optimal pulse width modulation (PWM) using the target PPFD for the plant-LED distance and the ambient PPFD. In this case, the final PPFD is controlled by the PWM signal and, hence, the proposed system generates the optimal level of the PWM signal while also reducing power consumption.

This paper is organized as follows: Section 2 gives the background for plant cultivation and conventional LED systems. In Section 3 we describe the proposed adaptive LED control method. Section 4 shows the hardware implementation of the proposed method. In Section 5, we evaluate the performance of the proposed and conventional methods. Finally, in Section 6, we conclude the paper.

\section{Background}

Table 1 shows results for the effects of LEDs with various wavelengths on the plants [7-12]. Ref. [7] experimented with materials produced in lettuce using red and blue LEDs separately. Red LEDs $(660 \mathrm{~nm}$ and $635 \mathrm{~nm}$ ) increased the phenolic concentration, and blue LEDs (476 nm) increased anthocyanin and carotenoids. Ref. [8] showed an experiment on cabbage. Anthocyanin was increased when red LEDs $(660 \mathrm{~nm})$ were used alone, and petiole elongation was promoted with increasing chlorophyll when using only blue LEDs $(470 \mathrm{~nm})$. Ref. [9] experimented with lettuce and green onions using red LEDs $(638 \mathrm{~nm})$ and natural light, and nitrate was decreased. Several studies have are also under way to promote plant growth using both red and blue LEDs [10-12]. In Ref. [10], anthocyanin content, antioxidant potential, and leaf area increased. Ref. [11] could slow down the flowering time of mustard and basil using red LEDs (660 and $635 \mathrm{~nm}$ ) and blue LEDs $(460 \mathrm{~nm})$. In Ref. [12], the stem length was reduced by using red LEDs $(660 \mathrm{~nm})$ and blue LEDs $(450 \mathrm{~nm})$.

Table 1. Effects of light emitting diode (LEDs) with various wavelengths on the plant.

\begin{tabular}{|c|c|c|c|}
\hline Reference & Plant & Light Source & Effect on Plant \\
\hline \multirow{2}{*}{ [7] } & Baby lettuce & Red LEDs (658 nm) & Increase of phenolics concentration \\
\hline & Baby lettuce & Blue LEDs (476 nm) & Increase of anthocyanin and carotenoids \\
\hline \multirow{2}{*}{ [8] } & Cabbage & Red LEDs $(660 \mathrm{~nm})$ & Increase of anthocyanin content \\
\hline & Cabbage & Blue LEDs (470 nm) & $\begin{array}{l}\text { Higher chlorophyll content promotion } \\
\text { petiole elongation }\end{array}$ \\
\hline [9] & Lettuce, Green onions & $\begin{array}{l}\text { Red LEDs }(638 \mathrm{~nm}) \\
\text { Natural illumination }\end{array}$ & Reduction of nitrate content \\
\hline [10] & Red leaf lettuce & $\begin{array}{l}\text { Red LEDs }(640 \mathrm{~nm}) \\
\text { Blue LEDs }(440 \mathrm{~nm})\end{array}$ & $\begin{array}{l}\text { Increase of anthocyanin content, } \\
\text { antioxidant potential and total leaf area }\end{array}$ \\
\hline [11] & Indian mustard, Basil & $\begin{array}{l}\text { Red LEDs (660 and } 635 \mathrm{~nm}) \\
\text { Blue LEDs }(460 \mathrm{~nm})\end{array}$ & Delay in plant transition to flowering \\
\hline [12] & Tomato seedlings & $\begin{array}{l}\text { Red LEDs }(660 \mathrm{~nm}) \\
\text { Blue LEDs }(450 \mathrm{~nm})\end{array}$ & Reduction of stem length \\
\hline
\end{tabular}

Table 2 shows how different kintypesds of light sources affect plants. Specifically, Ref. [10] increased the anthocyanin, antioxidant potential, and leaf area of the lettuce when $300 \mu \mathrm{mol} \mathrm{m} \mathrm{m} \mathrm{s}^{-1}$ was maintained using red LEDs (640 nm) and blue LEDs (440 nm). Ref. [13] increased vitamin C in mustard and spinach when $300 \mu \mathrm{mol} \mathrm{m}{ }^{-2} \mathrm{~s}^{-1}$ PPFD was maintained using red LEDs $(638 \mathrm{~nm})$ and high-pressure sodium (HPS) lamps. Ref. [14] increased phenolics, tocopherols, and antioxidant capacity of lettuce when maintained at a fixed value of $210 \mu \mathrm{mol} \mathrm{m}^{-2} \mathrm{~s}^{-1}$ for LED and $300 \mu \mathrm{mol} \mathrm{m}{ }^{-2} \mathrm{~s}^{-1}$ for HPS under the same conditions as [13]. Ref. [15] increased total dry weight of the lettuce when maintained at 100, 200, and $300 \mu \mathrm{mol} \mathrm{m}{ }^{-2} \mathrm{~s}^{-1}$ using red LEDs $(660 \mathrm{~nm})$ and blue LEDs $(450 \mathrm{~nm})$. In conclusion, various wavelengths and intensities could affect plants directly or indirectly depending on the type of plants. 
Table 2. Effects of light sources with the different photosynthetic photon flux density (PPFD) on the plant.

\begin{tabular}{|c|c|c|c|c|}
\hline Reference & Plant & Light Source & 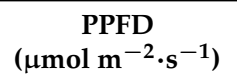 & Effect on Plant \\
\hline [10] & Red leaf lettuce & $\begin{array}{l}\text { Red LEDs (640nm); } \\
\text { Blue LEDs(440nm) }\end{array}$ & LED: 300 & $\begin{array}{l}\text { Increase of anthocyanin content, } \\
\text { antioxidant potential and leaf area }\end{array}$ \\
\hline [13] & Mustard, Spinach & $\begin{array}{l}\text { Red LEDs (638nm) } \\
\text { and HPS lamp }\end{array}$ & Total: 300 & Increase of vitamin $C$ content \\
\hline [14] & Baby lettuce & $\begin{array}{l}\text { Red LEDs (638nm) } \\
\text { and HPS lamp }\end{array}$ & $\begin{array}{l}\text { LED: } 210 \\
\text { HPS: } 300\end{array}$ & $\begin{array}{l}\text { Increase of phenolics, tocopherols, } \\
\text { antioxidant capacity, sugars }\end{array}$ \\
\hline [15] & Lettuce & $\begin{array}{l}\text { Red LEDs (660nm); } \\
\text { Blue LEDs(450nm) }\end{array}$ & $\begin{array}{l}\text { LED: } 100 \\
\text { LED: } 200 \\
\text { LED: } 300\end{array}$ & Increase of total dry weight \\
\hline
\end{tabular}

Figure 1 shows specific experimental results for 50 days that compare plant cultivation using sunlight and LED light of various wavelengths [16]. LED light is classified into red, blue, and combined red and blue wavelengths. In these experimental results, the growth rates of different plants were most highly influenced by the various conditions of light. Specifically, when looking at the plant height (stem length) results, camella grew the largest in sunlight, while melany showed the best efficiency when red and blue LEDs were used together. In terms of leaf area, both camella and melany crops showed the highest efficiency when combined with red and blue LEDs. This suggests that the optimal wavelength for the plants should be changed according to each plant and that the combination of red and blue LEDs has the best tendency.
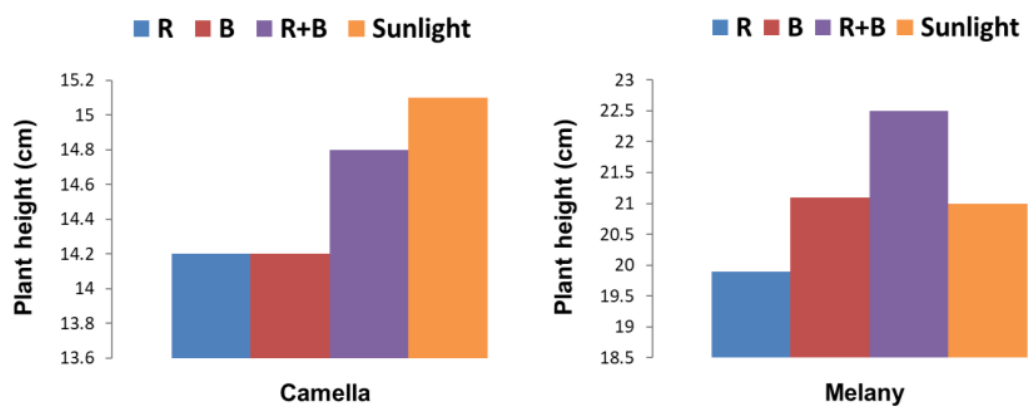

(a)
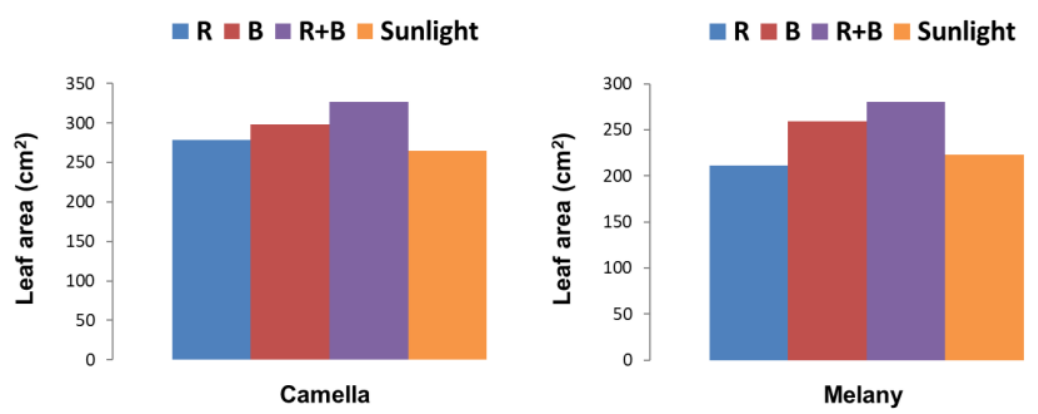

(b)

Figure 1. Comparison of plant growth using sunlight and LED lights [16].

Figure 2 shows experimental results for the growth of the leaf area and number of leaves in three Lycoris species for various illuminance [17]. In these results, different illuminance was required according to the plant species, and high illuminance was always detrimental to plants. Therefore, 
controlling the wavelength and intensity of light is a basic requirement for various plant cultivation. In this case, Since PPFD is used for plant growth, the PPFD must be controlled when controlling LEDs.

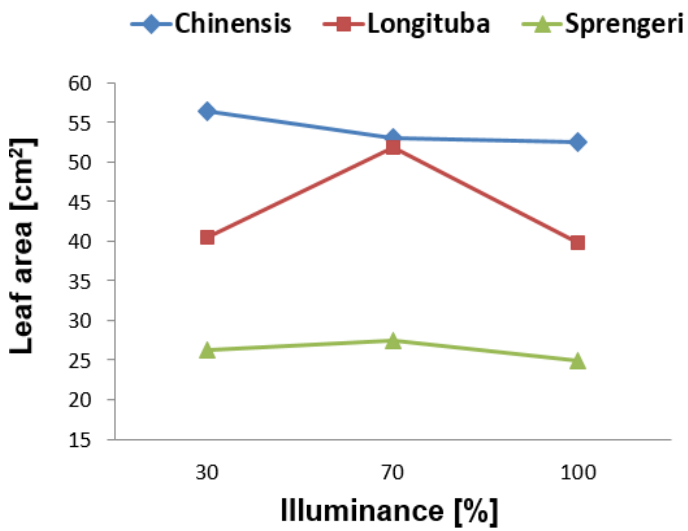

(a)

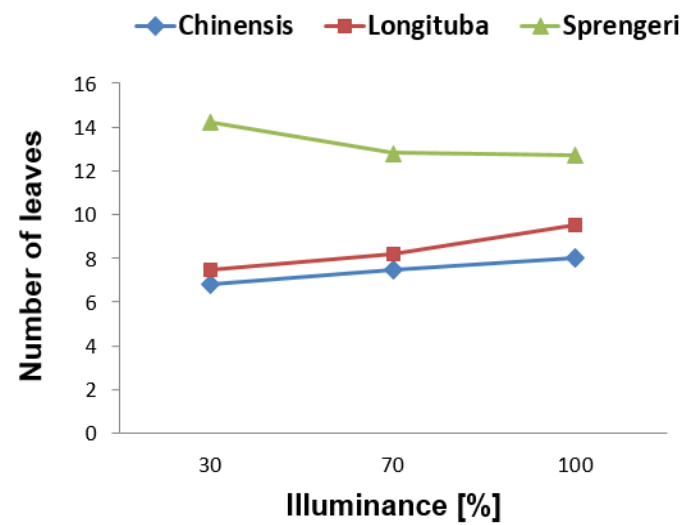

(b)

Figure 2. Comparison of plant growth according to illuminance [17].

Conventional LED systems always emit a fixed amount of PPFD and, hence, they cannot maintain the amount of PPFD required by a plant considering environmental factors such as the ambient PPFD and distance between the plant and LED system (plant-LED distance). Therefore, in some cases, a conventional LED system emits an excessive amount of PPFD, thereby consuming excessive power. Specifically, the LED system of [18] controls the PWM, but it cannot consider total PPFD adaptively and, thereby, is difficult to use for various plants. Therefore, it cannot emit the optimal PPFD considering the plant properties and consumes excessive power. The systems of $[19,20]$ use bar-type arrays with red and blue LEDs for plant cultivation. However, they also cannot control the PPFD according to changes in environmental factors, thereby inefficiently consuming power. In other approaches, [21] analyzed the spectral characteristics of two white LEDs and analyzed the growth of plants using each LED. In addition, [22] proposed a system that defines parameters that affect growth and adaptively controls these parameters. Ref. [2] reduced power by optimizing the spectral parameters of the LED. Specifically, in order to optimize the spectral parameters, it compared the energy efficiency in the target illumination system with different red and blue ratios of the LEDs.

In order to solve the problems of the above-mentioned systems and utilize the advantages, the proposed system enables controlling the wavelength of red and blue LEDs. It can also reduce power according to the target PPFD by using information from environmental change sensors. In addition, considering the ratio of exhaustion of non-renewable resources based on environmental sustainability and industry sustainability, a system should be developed that is more efficient than existing systems [23-25]. The proposed LED system will contribute to the growth of plants, preserve biodiversity and ecosystems, and consider sustainability with high efficiency compared to existing light sources.

\section{Proposed Adaptive LED Control Method}

Figure 3 shows the overall block diagram of the proposed adaptive LED control method. First, the proposed system measures the plant-LED distance using an infrared sensor and also measures the ambient illuminance using an illuminance sensor. Then, the illuminance is converted into PPFD for plant cultivation. It then calculates the optimal PWM using the target PPFD for the plant-LED distance and the ambient PPFD. In this case, the PPFD is controlled by the PWM signal and, hence, the proposed system generates the optimal level of the PWM signal considering the plant-LED distance and ambient PPFD. The specific operation of the proposed method shown below. 


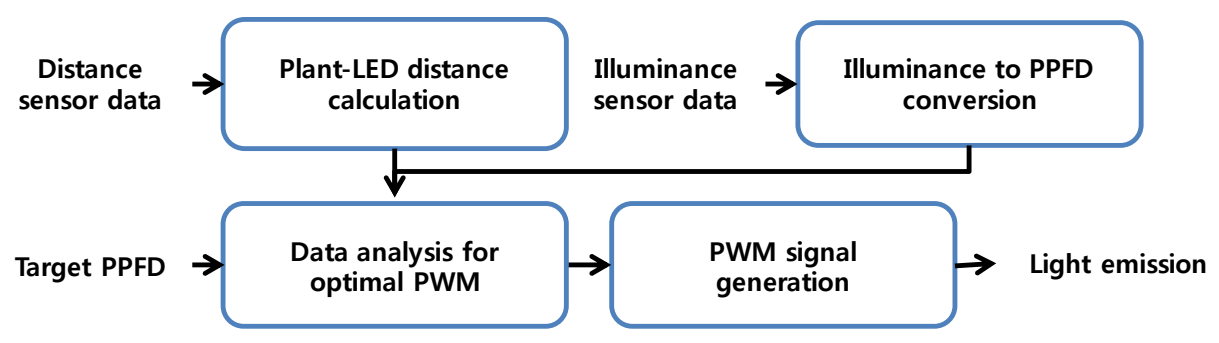

Figure 3. The proposed adaptive LED control method.

\subsection{Illuminance to PPFD Conversion}

Illumination is suitable for human eyes and cannot measure the effect on plants. Therefore, in order to consider plant growth, the illumination should be changed to PPFD. Table 3 shows the illuminance per PPFD [26]. PPFD can be converted using illuminance data and conversion factors. Especially, the proposed system requires these conversion factors because it provides a constant environment for plants considering both the sunlight and LED PPFD. Illumination to PPFD conversion is as follows:

$$
\begin{aligned}
& \text { PPFD }^{S}=\frac{I^{S}}{C^{S}} \\
& \text { PPFD }^{R}=\frac{I^{R}}{C^{R}} \\
& \text { PPFD }^{B}=\frac{I^{B}}{C^{B}}
\end{aligned}
$$

where $I^{S}, I^{R}$, and $I^{B}$ denote the sunlight, red LED, and blue LED illuminance data, respectively. $C^{S}, C^{R}$, and $C^{B}$ denote the sunlight, the red LED, and the blue LED conversion factor, respectively. PPFD is simply calculated by the conversion factor from Table 3 .

Table 3. The conversion from lux to PPFD varies under different light sources [26].

\begin{tabular}{cccccc}
\hline Light Source & Sunlight & Incandescent & Fluorescent Lamp & Red LED & Blue LED \\
\hline Conversion factor & 54.0 & 50.0 & 74.0 & 9.9 & 11.9 \\
\hline
\end{tabular}

\subsection{Inverse Square Law}

The inverse square law [27] is a property that the intensity of light is inversely proportional to the square of the distance. We use this law to reflect the relationship between illumination and distance in the proposed system. It is defined as follows:

$$
I^{L}=\left(\frac{1}{D_{P-L}}\right)^{2}
$$

where $I^{L}$ denotes the total LED illuminance and $D_{P-L}$ denotes the plant-LED distance.

We derive Equation (3) from Equation (2) to define the relationship between light and distance as follows:

$$
I_{c a n}^{L} \times D_{c a n}{ }^{2}=I_{r e f}^{L} \times D_{r e f}^{2}, \frac{I_{c a n}^{L}}{I_{r e f}^{L}}=\left(\frac{D_{r e f}}{D_{c a n}}\right)^{2}, I_{c a n}^{L}=\left(\frac{D_{r e f}}{D_{c a n}}\right)^{2} \times I_{r e f}^{L},
$$

where $I_{r e f}^{L}$ and $D_{r e f}$ denote the reference LED illuminance and the reference distance $(1 \mathrm{~m})$, respectively. In addition, $I_{c a n}^{L}$ and $D_{c a n}$ denote the candidate LED illuminance and the target distance, respectively. 


\subsection{PPFD Consideration}

The proposed system converts the illuminance of Equation (3) into PPFD using Equation (1) because the plant should consider the appropriate PPFD. First, in the formula defined in Equation (3), $I^{L}$ is the total light quantity of LED, so it is the same as Equation (4):

$$
\begin{aligned}
& I_{\text {can }}^{L}=I_{\text {can }}^{R}+I_{\text {can }}^{B} \\
& I_{\text {ref }}^{L}=I_{r e f}^{R}+I_{r e f}^{B}
\end{aligned}
$$

where $I_{r e f}^{R}$ and $I_{r e f}^{B}$ denote the reference illuminance of the red and blue LEDs, respectively. $D_{\text {ref }}$ denotes the reference distance $(1 \mathrm{~m})$. In addition, $I_{c a n}^{R}$ and $I_{c a n}^{B}$ denote candidate illuminance of the red and blue LEDs, respectively. $D_{\text {can }}$ denotes the candidate distance.

Using the conversion factor, the red and blue illuminance in Equation (4) is converted to Equation (5), which is the PPFD value:

$$
\frac{I_{c a n}^{R}}{C_{c a n}^{R}}+\frac{I_{c a n}^{B}}{C_{c a n}^{B}}=\left(\frac{D_{r e f}}{D_{c a n}}\right)^{2} \times\left(\frac{I_{r e f}^{R}}{C_{r e f}^{R}}+\frac{I_{r e f}^{B}}{C_{r e f}^{B}}\right), P P F D_{c a n}^{L}=\left(\frac{D_{r e f}}{D_{c a n}}\right)^{2} \times P P F D_{r e f}^{L}
$$

where PPFD $L$ can and PPFD $D_{\text {ref }}^{L}$ denote the candidate PPFD of the LEDs and the reference PPFD of the LEDs, respectively.

$$
P P F D^{T}=P P F D_{c a n}^{L}+P P F D^{S},
$$

where $P P F D^{T}$ and $P P F D^{S}$ denote the target total PPFD and sunlight PPFD, respectively.

\subsection{Optimal PWM Determination}

After analyzing the data, the PWM signal levels should be determined for various distances and sunlight PPFD after the target PPFD has been determined. First, the final PPFD is determined when the difference between the target and candidate PPFDs are minimized as follows:

$$
i_{p}^{F}=\underset{i_{p}}{\operatorname{argmin}}\left\{P P F D_{\text {tar }}^{T}-P P F D^{T}\left(i_{p}, i_{d}\right)\right\},
$$

where $i_{p}$ and $i_{d}$ denote the indices of the PWM signal level and the distance, respectively. In addition, PPFD $D_{\text {tar }}^{T}$ and $i_{p}^{F}$ denote the total target PPFD and the optimal PWM. Using $i_{p}^{F}$, we can control the LEDs to match the target PPFD.

\section{Hardware Implementation}

Figure 4 shows the overall system, which is divided into the LED arrays, metal-oxidesemiconductor field-effect transistors (MOSFETs), gate driver integrated circuits (ICs), a microcontroller, and the power supply and conversion. As shown in the figure of LED arrays, one line consists of 12 LEDs ( $4 \times 3$ LEDs). In order to meet the electrical specification, one LED is actually modeled as three in the circuit schematic. The wavelengths of the red and blue LEDs are $660 \mathrm{~nm}$ and $460 \mathrm{~nm}$, respectively. Their electrical specifications are $2.4 \mathrm{~V}$ and $90 \mathrm{~mA}$ (red LED) and $2.6 \mathrm{~V}$ and $90 \mathrm{~mA}$ (blue LED) and, hence, the proposed system consumes almost $40 \mathrm{~W}$ power for the LEDs. To control the LED PPFD, a micro-controller and MOSFET-based switching circuit are used. For the micro-controller, an Arduino Mega in an ATmega is used and the adaptive PPFD control method is implemented in software. Specifically, the PWM signal is changeable to match the target PPFD, and the microcontroller controls the duty cycle of the signal, which can vary from $0 \mathrm{~V}$ to $5 \mathrm{~V}$ in a square form with a frequency of $980 \mathrm{~Hz}$. After the micro-controller generates the PWM signal, considering the plant-LED distance and ambient PPFD, the voltage of its PWM signal switches the MOSFET on or off, thereby controlling the current flow and LED PPFD. The gate driver and 
buffer are to prevent the effects of the inverse current and inverse voltage on the microcontroller. The DC-DC convertor converts $12 \mathrm{~V}$, which is for the LED driving voltage, into $5 \mathrm{~V}$ for the voltage of control part. In addition, cooling fans were installed to prevent the system from overheating. Each fan operates at $1800 \mathrm{RPM}$ to dissipate heat and each fan consumes additional power of $1.2 \mathrm{~W}$. The power consumption, except for that of the LED array, is almost $12 \mathrm{~W}$ and, hence, the power consumption of the total system is $52.5 \mathrm{~W}$.

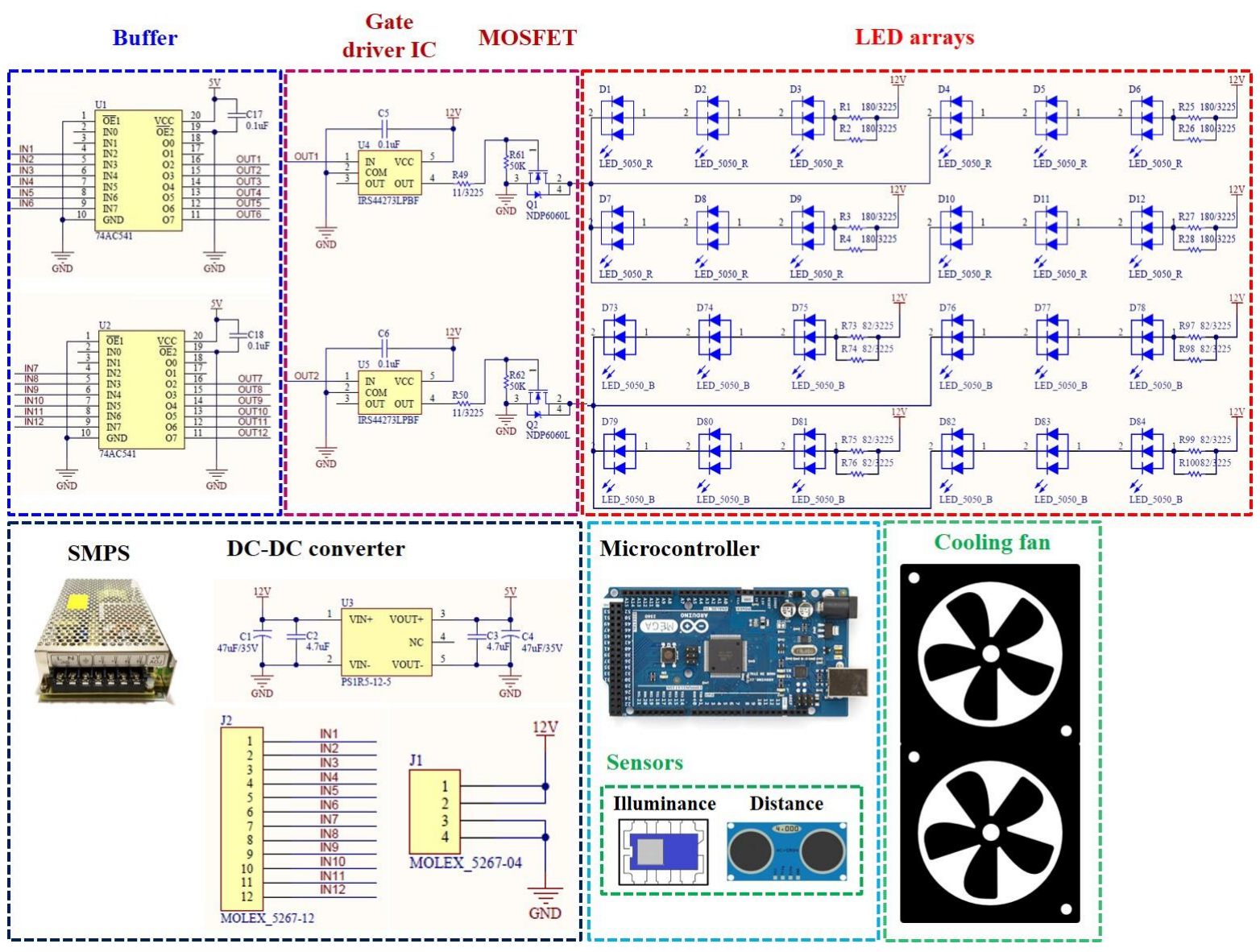

Figure 4. The overall circuit diagram of the proposed system.

Figure 5 shows the implemented prototype of the proposed system. The proposed system uses a stainless steel case to enhance its thermal conductivity. Figure 5a shows the concept of the proposed system. The front side (Figure 5b) consists of the LED array and MOSFETs, and the back side (Figure 5c) has the operation switch and illumination sensor that measures the ambient illumination. The inner part (Figure 5d) contains the microcontroller, switching mode power supply (SMPS), infrared distance sensor, and cooling fan for the system. In the proposed system, the components, except the LEDs, consist of a module for the LED control unit and a cooling fan. The cooling fan increases power consumption, but they are indispensable to the stability of system operation. Specifically, active fans are used to reduce the high temperatures caused by the heat of the LED array and switched-SMPS. Using these system modules, the proposed system can control the red and blue LEDs according to the environmental conditions, as shown in Figure 5e. 


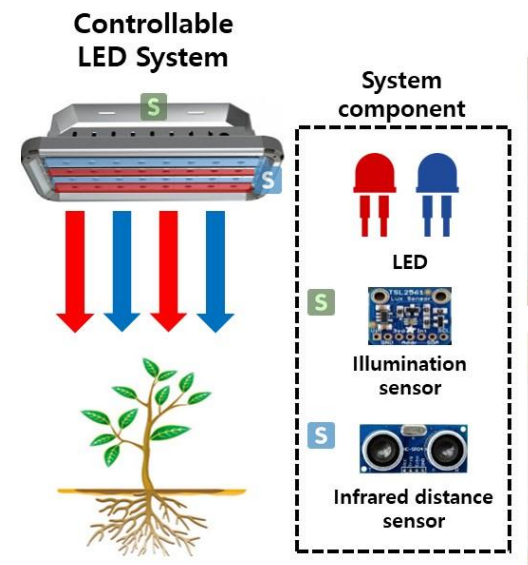

(a)

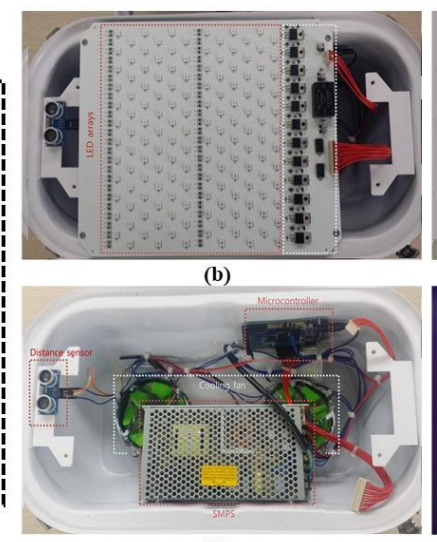

(d)

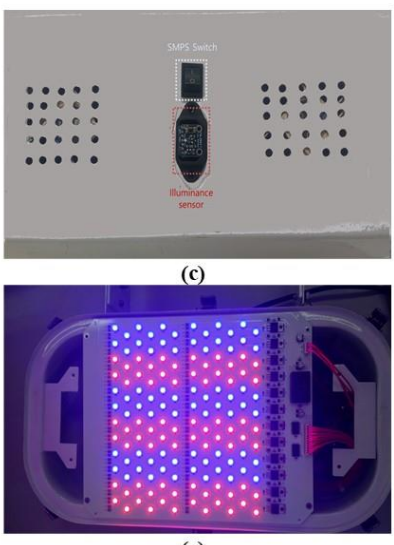

(e)

Figure 5. Implemented prototype of the proposed system: (a) overall system; (b) front side; (c) back side; (d) functional modules; and (e) system operation.

\section{Experiment Result}

\subsection{Power Model}

For the power measurement, the illuminance to power conversion model [28] was used:

$$
P_{(W)}=\frac{\phi_{v}(\operatorname{lm})}{\eta(\operatorname{lm} / W)}
$$

In this case, the proposed system uses PPFD, where the unit is $\mu \mathrm{mol} \mathrm{m}{ }^{-2} \mathrm{~s}^{-1}$ (micromoles per $\mathrm{m}^{2}$ per second), but this model is based on the luminous flux, where the unit is lumens. Therefore, first, the PPFD should be converted into illuminance $\left(I_{v}\right)$ as follows:

$$
I_{V(l u m)}=I_{P P F D}\left(\mu m o l m^{-2} s^{-1}\right) \times C
$$

where $I_{P P F D}$ and $C$ denote the PPFD and conversion factor, respectively. Then, the illuminance $\left(I_{v}\right)$ should be converted into luminous flux $\left(\varphi_{v}\right)$ using the following equation:

$$
\phi_{v}(\operatorname{lm})=I_{V(l u m)} \times A_{\left(m^{2}\right)}
$$

Finally, using Equation (4), the power can be calculated as follows:

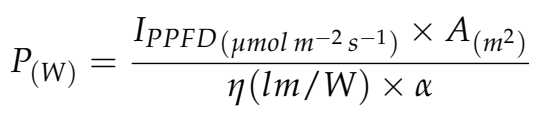

where $\eta$ denotes the luminous efficacy, which is the efficiency when the source provides visible light from electricity. The luminous efficacy of the red LEDs was $50 \mathrm{~lm} / \mathrm{W}$, and the luminous efficacy of blue LEDs was $26 \mathrm{~lm} / \mathrm{W}$ in the proposed system.

\subsection{Power Consumption Evaluation}

Table 4 shows the specific experimental data for various plant-LED distances and ambient PPFD levels. In addition, the proposed system was also compared with a conventional system that cannot consider the plant-LED distance and ambient PPFD. Specifically, the conventional system could not control the LED PPFD and, hence, the PPFD was significantly increased when the plant-LED distance was small. The maximum PPFD was $496 \mu \mathrm{mol} \mathrm{m}^{-2} \mathrm{~s}^{-1}$, which was almost eight times higher than the target PPFD. On the other hand, the proposed LED system could control the PPFD considering the 
environmental conditions and, hence, the target PPFD was maintained and power consumption was changed from 17 to $52.5 \mathrm{~W}$.

Table 4. pulse width modulation (PWM) signal and power consumption when the distance between a plant and the proposed LED system and ambient PPFD is changed.

\begin{tabular}{|c|c|c|c|c|c|c|c|}
\hline \multirow{2}{*}{$\begin{array}{l}\text { Ambient PPFD } \\
\left(\mu \mathrm{mol} \mathrm{m} \mathrm{m}^{-2} \mathrm{~s}^{-1}\right)\end{array}$} & \multirow{2}{*}{$\begin{array}{l}\text { Distance } \\
\text { (cm) }\end{array}$} & \multicolumn{3}{|c|}{ Conventional System } & \multicolumn{3}{|c|}{ Proposed System } \\
\hline & & PWM & $\begin{array}{l}\text { Power } \\
\text { (W) }\end{array}$ & 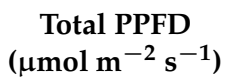 & PWM & $\begin{array}{l}\text { Power } \\
\text { (W) }\end{array}$ & 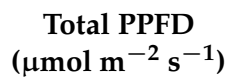 \\
\hline \multirow{4}{*}{20} & 100 & 255 & 52.5 & 101 & 255 & 52.5 & 101 \\
\hline & 80 & 255 & 52.5 & 127 & 140 & 34 & 102 \\
\hline & 60 & 255 & 52.5 & 230 & 110 & 28.9 & 99 \\
\hline & 40 & 255 & 52.5 & 476 & 45 & 18.7 & 101 \\
\hline \multirow{4}{*}{30} & 100 & 255 & 52.5 & 111 & 223 & 47.4 & 97 \\
\hline & 80 & 255 & 52.5 & 137 & 122 & 31.1 & 95 \\
\hline & 60 & 255 & 52.5 & 240 & 96 & 27 & 98 \\
\hline & 40 & 255 & 52.5 & 486 & 39 & 18 & 97 \\
\hline \multirow{4}{*}{40} & 100 & 255 & 52.5 & 121 & 191 & 42.3 & 102 \\
\hline & 80 & 255 & 52.5 & 147 & 105 & 28.4 & 98 \\
\hline & 60 & 255 & 52.5 & 250 & 82 & 24.7 & 101 \\
\hline & 40 & 255 & 52.5 & 496 & 33 & 17 & 101 \\
\hline
\end{tabular}

In Figures 6 and 7, A.P. in the figure means the ambient PPFD. First, Figure 6 compared PPFDs for LEDs with the conventional full-on and proposed modes in the proposed system. When A.P. was $20 \mu \mathrm{mol} \mathrm{m}{ }^{-2} \mathrm{~s}^{-1}$ and the LEDs were fully on, the conventional mode emitted $476 \mu \mathrm{mol} \mathrm{m} \mathrm{m}^{-2} \mathrm{~s}^{-1}$, which is an excessive amount in some cases. On the other hand, the proposed mode maintained $100 \mu \mathrm{mol} \mathrm{m}{ }^{-2} \mathrm{~s}^{-1}$ even though A.P. was changed and the distance from the device to the plant was changed. These results show that the proposed method could reduce the power compared to the conventional method while providing the PPFD suitable for the plant. Figure 7 compared the total power consumed in the proposed system in various situations. The results show that the LED full on mode consumed $52.5 \mathrm{~W}$, which was the maximum output power, regardless of the distance, but the proposed method could reduce the total power of the system according to the ambient light intensity and distance.

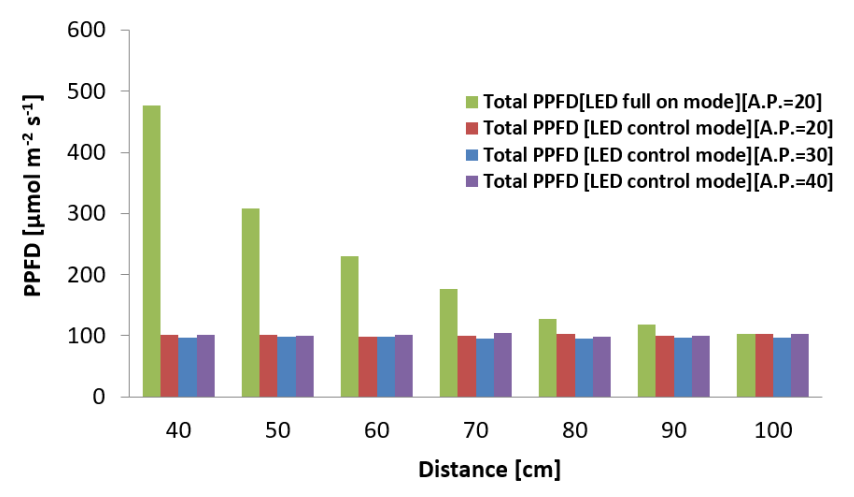

Figure 6. Total PPFD comparison according to various distances and ambient PPFD. 


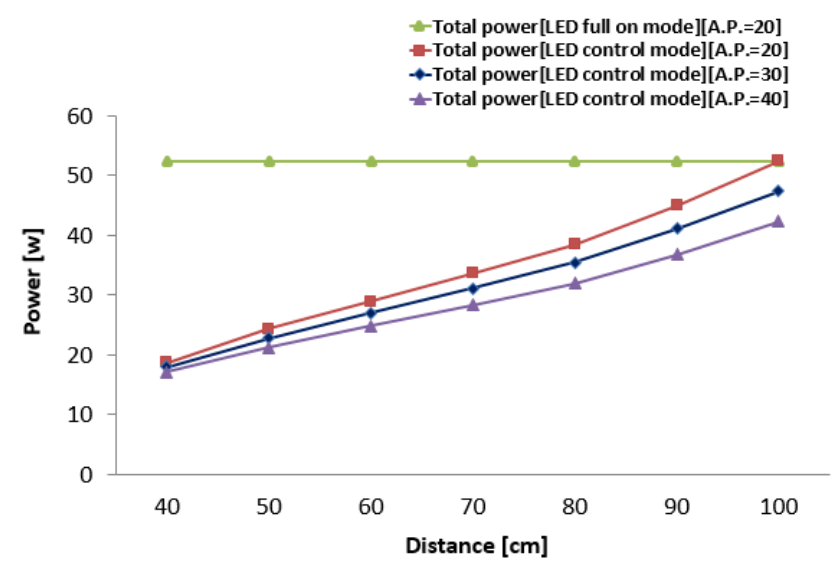

Figure 7. Total power comparison according to various distances and ambient PPFD.

Figure 8 shows the changes in the wavelength that the proposed system can emit in a plant cultivation environment. In the proposed system, red or blue LEDs could be operated individually, and red and blue LEDs could be operated simultaneously. Figure 8 shows that an arbitrary wavelength could be emitted as an example of the above. In addition, a plant growth experiment was conducted to estimate the growth of lettuce and leek using the proposed system in the actual room. When referring to [29], the result of 24/0 (light/dark) was better than those of 6/18 (light/dark), 9/15 (light/dark), 12/12 (light/dark), and 18/6 (light/dark) in terms of the growth for stem length and leaf area. We also controlled PWM signals according to the ambient light throughout the 24-h period over two weeks, and emitted a PPFD of $100 \mu \mathrm{mol} \mathrm{m}{ }^{-2} \mathrm{~s}^{-1}$. As a result, as shown in Figure 9, it was confirmed that the leek was raised to $5.6 \mathrm{~cm}$ and the lettuce grew $4.4 \mathrm{~cm}$ in the sunlight environment. However, when the proposed system was used, it was confirmed that the leeks grew by $7.3 \mathrm{~cm}$ and the lettuce grew by $6.3 \mathrm{~cm}$. Therefore, it was confirmed that the average degree of plant growth was improved by $2 \mathrm{~cm}$. This experiment was the result of two weeks. In order to increase the reliability, additional factors to judge the growth of plants, such as chlorophyll content and leaf area, will be needed in future work.

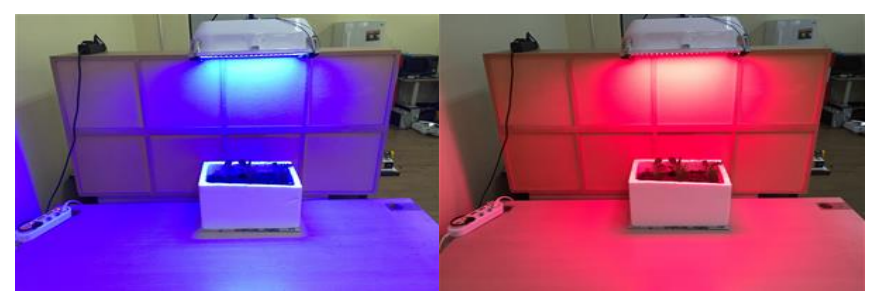

(a)

(b)

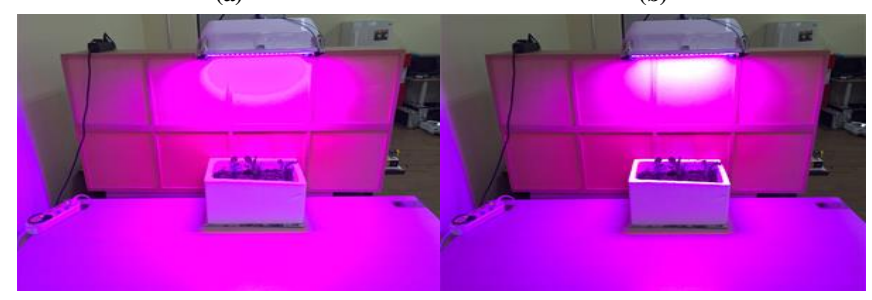

(c)

(d)

Figure 8. Plant cultivation test for the proposed LED control system using red/blue LED PWM signals: (a) $0 / 255$; (b) 255/0; (c) 128/128; and (d) 255/255. 


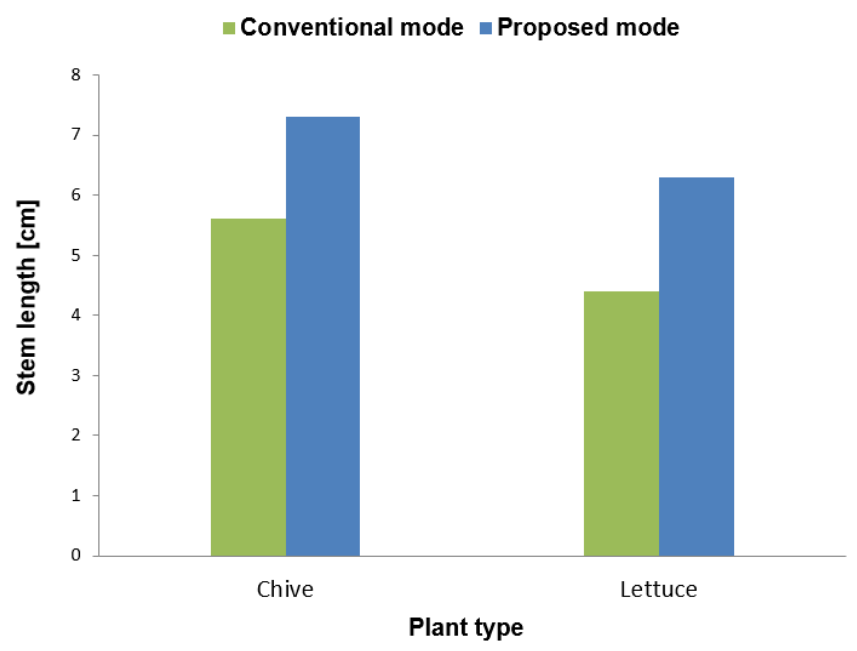

Figure 9. Plant cultivation comparison between conventional and proposed modes over two weeks.

In terms of power consumption, the proposed system could change the power consumption from 16.5 W to $52.5 \mathrm{~W}$ as shown in Figure 10. Specifically, in the indoor environment, the PPFD could vary greatly depending on the ambient illumination. The proposed system supplied the PPFD to the plant in accordance with this. Power consumption was high until 18:00, and low until 08:00, when the room was not lit, while the lighting was controlled from 09:00 to 17:00 according to the indoor lighting environment to reduce power and provide a constant PPFD to the plants. In the power consumption, the conventional system consumed 625 Wh because they did not control LEDs all day, but the proposed method could reduce the power by $167 \mathrm{Wh}$ per day from 07:00 to 18:00. This result can be expected to vary by season or by weather impact, but can be reduced by approximately $60 \mathrm{kWh}$ over a year.

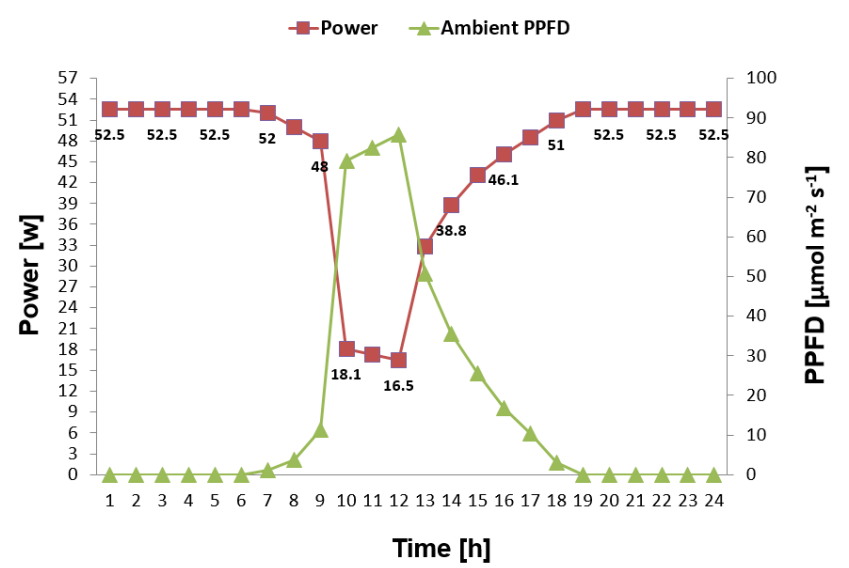

Figure 10. Power consumption with respect to the different ambient PPFDs for a fixed distance of $0.9 \mathrm{~m}$.

\section{Conclusions}

This paper proposed a novel LED control system that considers environmental factors for plant cultivation. The proposed system used an infrared sensor and illuminance sensor to measure the plant-LED distance and ambient illuminance, respectively. Then, the ambient illuminance was converted into PPFD for the plant cultivation. It calculated the optimal relationship between the environmental factors and LED PPFD. For the hardware implementation, red and blue LED arrays were used. In addition, MOSFET-based switching circuits, a microcontroller, and cooling fans were used. In experiments using the implemented hardware, the proposed LED system maintained the 
target PPFD even though the distance and ambient PPFD were changed. In addition, the power consumption of the proposed system was maximally $68 \%$ lower than that of the conventional system.

The proposed system increased the efficiency of renewable resources in terms of environmental sustainability. In addition, LED power could be adjusted to optimize the power consumption according to the plant. Since the ambient PPFD was taken into consideration, energy efficiency over time also increased and industry sustainability could be considered. In addition, the proposed system was a system with high power efficiency. However, recognizing any plant and automatically outputting the optimized wavelength will help to increase power efficiency and plant growth. Additionally, because it uses only distance and ambient light sensors, it can be vulnerable to growing plants that are sensitive to humidity or temperature conditions. Further research is needed on these subjects. In the future, various solutions to the food shortage problem will be needed. Research on plant growth will continue as a promising method.

Acknowledgments: This research was supported by Korea Electric Power Corporation through Korea Electrical Engineering and Science Research Institute. [grant number: R15XA03-08]

Author Contributions: Yong Deok Ahn and Suk-Ju Kang conceived and designed the system and method; Yong Deok Ahn, and Suk-Ju Kang performed the experiments and analyzed the results; Yong Deok Ahn, Sungwoo Bae and Suk-Ju Kang contributed to the system's development; and Yong Deok Ahn, Sungwoo Bae and Suk-Ju Kang wrote the paper.

Conflicts of Interest: The authors declare no conflict of interest.

\section{References}

1. Baldos, U.L.C.; Hertel, T.W. Global food security in 2050: The role of agricultural productivity and climate change. Aust. J. Agric. Resour. Econ. 2014, 58, 554-570. [CrossRef]

2. Poulet, L.; Massa, G.D.; Morrow, R.C.; Bourget, C.M.; Wheeler, R.M.; Mitchell, C.A. Significant reduction in energy for plant-growth lighting in space using targeted LED lighting and spectral manipulation. Life Sci. Space Res. 2014, 2, 43-53. [CrossRef]

3. Reith, J.H.; Deurwaarder, E.P.; Hemmes, K.; Curvers, A.; Kamermans, P.; Brandenburg, W.A.; Lettings, G. Bio-Offshore: Grootschalige Teelt Van Zeewieren in Combinatie Met Offshore Windparken in de Noordzee. Available online: https:/ / www.ecn.nl/publications/ECN-C--05-008 (accessed on 13 February 2017).

4. Bourget, C.M. An introduction to light-emitting diodes. HortScience 2008, 43, 1944-1946.

5. Morimoto, T.; Torii, T.; Hashimoto, Y. Optimal control of physiological processes of plants in a green plant factory. Control Eng. Pract. 1995, 3, 505-511. [CrossRef]

6. Morrow, R.C. LED lighting in horticulture. HortScience 2008, 43, 1947-1950.

7. Li, Q.; Kubota, C. Effects of supplemental light quality on growth and phytochemicals of baby leaf lettuce. Environ. Exp. Bot. 2009, 67, 59-64. [CrossRef]

8. Mizuno, T.; Amaki, W.; Watanabe, H. Effects of monochromatic light irradiation by LED on the growth and anthocyanin contents in leaves of cabbage seedlings. In Proceedings of the VI International Symposium on Light in Horticulture, Tsukuba, Japan, 15-19 November 2009.

9. Samuolienè, G.; Urbonavičiūtè, A.; Duchovskis, P.; Bliznikas, Z.; Vitta, P.; Žukauskas, A. Decrease in nitrate concentration in leafy vegetables under a solid-state illuminator. HortScience 2009, 44, 1857-1860.

10. Stutte, G.W.; Edney, S.; Skerritt, T. Photoregulation of bioprotectant content of red leaf lettuce with light-emitting diodes. HortScience 2009, 44, 79-82.

11. Tarakanov, I.; Yakovleva, O.; Konovalova, I.; Paliutina, G.; Anisimov, A. Light-emitting diodes: on the way to combinatorial lighting technologies for basic research and crop production. In Proceedings of the VII International Symposium on Light in Horticultural Systems, Wageningen, The Netherlands, 15-18 October 2012.

12. Nanya, K.; Ishigami, Y.; Hikosaka, S.; Goto, E. Effects of blue and red light on stem elongation and flowering of tomato seedlings. In Proceedings of the VII International Symposium on Light in Horticultural Systems, Wageningen, The Netherlands, 15-18 October 2012. 
13. Bliznikas, Z.; Žukauskas, A.; Samuoliene, G.; Viršile, A.; Brazaityte, A.; Jankauskiene, J.; Duchovskis, P.; Novičkovas, A. Effect of supplementary pre-harvest LED lighting on the antioxidant and nutritional properties of green vegetables. Acta Hortic. 2012, 939, 85-91. [CrossRef]

14. Samuolienè, G.; Sirtautas, R.; Brazaitytè, A.; Viršilè, A.; Duchovskis, P. Supplementary red-LED lighting and the changes in phytochemical content of two baby leaf lettuce varieties during three seasons. J. Food Agric. Environ. 2012, 10, 701-706.

15. Furuyama, S.; Ishigami, Y.; Hikosaka, S.; Goto, E. Effects of blue/red ratio and light intensity on photomorphogenesis and photosynthesis of red leaf lettuce. Acta Hortic. 2014, 1037, 317-322. [CrossRef]

16. Heo, J.W.; Lee, Y.B.; Kim, D.E.; Chang, Y.S.; Chun, C. Effects of supplementary LED lighting on growth and biochemical parameters in dieffenbachia amoena 'Camella' and Ficus elastica 'Melany'. Korean J. Hortic. Sci. Technol. 2010, 28, 51-58.

17. Meng, P.; Ge, Y.; Cao, Q.; Chang, J.; Pan, P.; Liu, C.; Lu, Y.; Chang, S.X. Growth and photosynthetic responses of three Lycoris species to levels of irradiance. HortScience 2008, 43, 134-137.

18. Olvera-Gonzalez, E.; Alaniz-Lumbreras, D.; Ivanov-Tsonchev, R.; Villa-Hernández, J.; Olvera-Olvera, C.; González-Ramírez, E.; Araiza-Esquivel, M.; Torres-Argüelles, V.; Castaño, V. Intelligent lighting system for plant growth and development. Comput. Electron. Agric. 2013, 92, 48-53. [CrossRef]

19. Choi, H.G.; Moon, B.Y.; Kang, N.J. Effects of LED light on the production of strawberry during cultivation in a plastic greenhouse and in a growth chamber. Sci. Hortic. 2015, 189, 22-31. [CrossRef]

20. Folta, K.M.; Childers, K.S. Light as a growth regulator: Controlling plant biology with narrow-bandwidth solid-state lighting systems. HortScience 2008, 43, 1957-1964.

21. Burattini, C.; Mattoni, B.; Bisegna, F. The impact of spectral composition of white LEDs on spinach (Spinacia oleracea) Growth and Development. Energies 2017, 10, 1383. [CrossRef]

22. Tai, W.-C.; Tseng, Y.-C.; Chiang, I.-T.; Lin, Y.-S.; Chung, W.-Y.; Wu, K.-W.; Yeh, Y.-H. Development of a multi-parameter plant growth monitoring and control system for quality agriculture application. In Proceedings of the 2017 International Conference on Applied System Innovation, Sapporo, Japan, 13-17 May 2017.

23. Centobelli, P.; Cerchione, R.; Esposito, E. Environmental sustainability in the service industry of transportation and logistics service providers: Systematic literature review and research directions. Transp. Res. Part Transp. Environ. 2017, 53, 454-470. [CrossRef]

24. Rajeev, A.; Pati, R.K.; Padhi, S.S.; Govindan, K. Evolution of sustainability in supply chain management: A literature review. J. Clean. Prod. 2017, 162, 299-314. [CrossRef]

25. Correia, E.; Carvalho, H.; Azevedo, S.G.; Govindan, K. Maturity models in supply chain sustainability: A Systematic Literature Review. Sustainability 2017, 9, 64. [CrossRef]

26. Lee, S.; Park, S. Energy savings of home growing plants by using daylight and LED. In Proceedings of the Sensors Applications Symposium, Galveston, TX, USA, 19-21 February 2013.

27. Liao, M.; Wang, L.; Yang, R.; Gong, M. Light fall-off stereo. In Proceedings of the IEEE Conference on Computer Vision and Pattern Recognition, Minneapolis, MI, USA, 17-22 June 2007.

28. Lan, L.; Tan, Y.K. Advanced building energy monitoring using wireless sensor integrated Energy Plus platform for personal climate control. In Proceedings of the 2015 IEEE 11th International Conference on Power Electronics and Drive Systems (PEDS), Sydney, Australia, 9-12 June 2015; pp. 567-574.

29. Nhí, P.N.; Ba, T.T.; Thúc, L.V.; Long, P.N.; Non, T.T.S.; Thủy, V.T.B. Effects of color LED light intensities and different photoperiod regimes on growth of hydroponic lettuce. Can Tho Univ. J. Sci. 2016, 2, 1-7.

(C) 2017 by the authors. Licensee MDPI, Basel, Switzerland. This article is an open access article distributed under the terms and conditions of the Creative Commons Attribution (CC BY) license (http://creativecommons.org/licenses/by/4.0/). 